\title{
Solid pseudopapillary neoplasm of the pancreas: report of two pediatric cases
}

\begin{abstract}
Solid pseudopapillary neoplasm of the pancreas (SPNP) is a rare malign tumor found in childhood. It is more frequent in young women on the second or third decade of their lives. Clinical features go from asymptomatic, abdominal pain, palpable mass, nausea, vomiting and jaundice to pancreatitis. Although the tumor is diagnosed in its necrotic phase this malignant exocrine tumor has a good prognosis after its excision. We report 2 patients who presented a SPNP at 6 and $9 \mathrm{y} / \mathrm{o}$, one of them male (even rarer within the SPNP). In one of the two patients (Case 2) tumor histopathology study was found on his first phase. So, SPNP should be ruled every time we find an abdominal mass in children.
\end{abstract}

Special Issue - 2018

\author{
Valer-Montoya Catherine,' Quiroz - Portella \\ Rafael,' Alvarado Germán F,' Díaz-Ferrer \\ Javier, ${ }^{2}$ Carranza Mariela, ${ }^{2}$ Palomino - \\ Portilla Eugenio, ${ }^{3}$ Piscoya Alejandro',3 \\ 'School of Medicine, Peruvian University of Applied Sciences, \\ Peru \\ ${ }^{2}$ Hospital Essalud Edgardo Rebagliati Martins Hospital, Peru \\ ${ }^{3}$ Guillermo Kaelin Hospital of the Source, Essalud, Peru
}

\author{
Correspondence: Valer-Montoya Catherine, School of \\ Medicine, Peruvian University Of Applied Sciences, Alameda San \\ Marcos, Block 2, Chorrillos, Peru, Tel (+5I I) 3133333, \\ Email u201011748@upc.edu.pe \\ Received: December 14, 2017 | Published: September 19, \\ 2018
}

Abbreviations: SPNP, Solid pseudopapillary neoplasm of the pancreas; CT, computed tomography; PE, physical examination; AFP, alpha fetoprotein; CEA, carcinoembryonic antigen; SSCT, spiral scan CT; AP, anatomopathology; IHC, Immunohistochemistry; MRI, magnetic resonance imaging; NSE, neuron specific enolase

\section{Introduction}

Solid pseudopapillary neoplasm of the pancreas (SPNP) is a rare exocrine tumor, ${ }^{1}$ which represents between $0.1-2.8 \%$ of all pancreatic tumors. ${ }^{2}$ First described by Frantz in $1959,{ }^{2-4}$ SPNP commonly presents on young women ${ }^{1-6}$ around the second and third decades of life. ${ }^{2,3}$ It is a low grade malignant tumor, ${ }^{6}$ with a 5 year survival rate of up to $100 \% .^{5}$ The tumor can be asymptomatic. ${ }^{1-6}$ Diagnose can be done with a computed tomography $(\mathrm{CT})^{4}$ and is confirmed by biopsy. ${ }^{3,4}$ The curative treatment is the complete resection of the tumor. ${ }^{1-6}$

\section{Case presentations}

\section{Case I}

A 6 y/o female presents with a 2 months history of left upper quadrant pain, early satiety, post prandial nausea and occasional vomits. No remarkable signs were found on physical examination (PE). An abdominal ultrasound (US) revealed a retroperitoneal mass. Laboratory tests showed CA 19-9, alpha fetoprotein (AFP) and carcinoembryonic antigen (CEA) on normal range. A spiral scan CT (SSCT) (Figure 1) disclosed a hypodense cystic lesion with peripheral contrast enhancement of $5.8 \times 4.9 \mathrm{~cm}$ placed on the pancreas tail displacing spleen, left kidney and stomach. The tumor was surgically removed by laparoscopy and anatomopathology (AP) revealed a $7.5 \times 6.0 \times 4.0 \mathrm{~cm}$ tumor (Figure 2 ) with a $60 \%$ black-purplish necrotic area surrounded by white viable pancreatic tissue. Microscopy confirmed a SPNP (Figure 2). Immunohistochemistry (IHC) showed neoplastic cell positive to cycline D1, CD-99 paranuclear dot (Figure 2), vimentin, $\mathrm{Ki}-67<1 \%$, weak progesterone receptor; and, negative E-cadherin, CD-56, estrogen receptor and CD-34. The patient was discharged on the tenth day post-surgery and received a 12 months close follow up without evidence of recurrence.

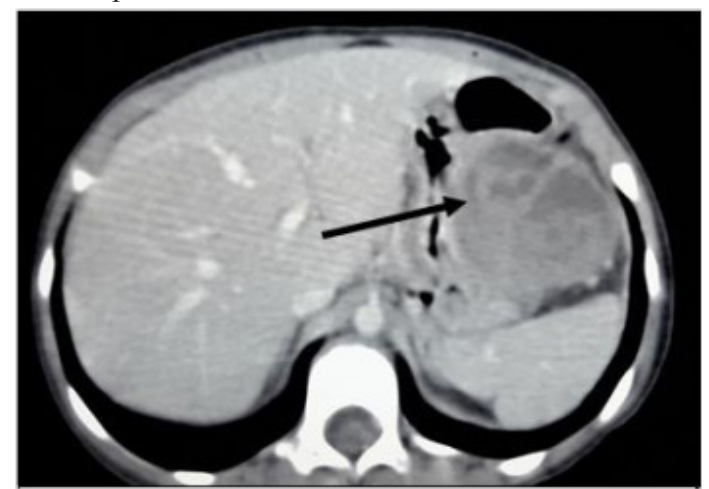

Figure I Arrow shows the tumor

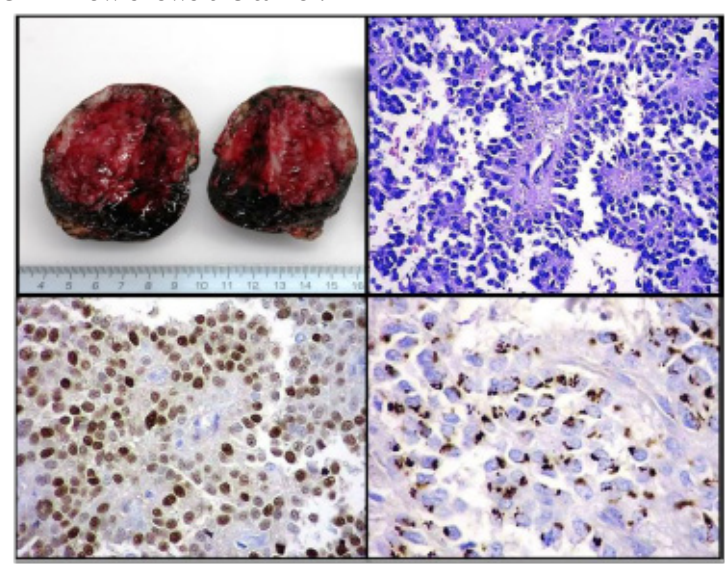

Figure 2 Upper left corner: Macrophotography of the tumor. Upper right corner: Microphotography showing pseudopapillary pattern and hyalinized perivascular stroma. Cells nucleuses are peripheral to vascular axis. Lower: Microphotography showing positive inmunereactivity to cycline dl tumor cell nucleuses (left) and cd-99 reactivity paranuclear dot (right) 


\section{Case 2}

A $9 \mathrm{y} / \mathrm{o}$ male, with history of appendectomy and peritonitis, Meckel diverticulum's surgery 6 years ago and chronic constipation came to the hospital complaining of 1 year of mild to moderate colic epigastric intermittent pain. Two months before admission he had abdominal distension, intermittent vomits and sporadic headache. His primary care physician ordered an abdominal US which showed a $2.5 \times 1.9 \mathrm{~cm}$ hypoechogenic ovoid lesion; later, the SSCT and Magnetic resonance imaging (MRI) revealed a $2.1 \times 1.6 \times 1.8 \mathrm{~cm}$ tumor on the pancreas body (Figure 3). Tumor markers CA 19-9 (Normal $<37 \mathrm{U} / \mathrm{mL}$ ) and AFP were normal. An Endoscopic Ultrasound (EUS) biopsy showed only adipose tissue. A distal pancreatectomy of the neck, body and tail was performed. AP revealed a $1.7 \times 1.4 \times 1.2 \mathrm{~cm}$ tumor lesion on the tail of the pancreas. Microscopy showed solid and pseudopapillary patterns on tumor cells (Figure 4). On IHC tumor cells were positive for cycline D1 (Figure 4), progesterone receptors, Ki-67 $<2 \%$ and negative for pan cytokeratin, CD-99, estrogen receptors, chromogranin, synaptophysin and not representative vimentin. The patient was discharged at 10 days post-surgery.

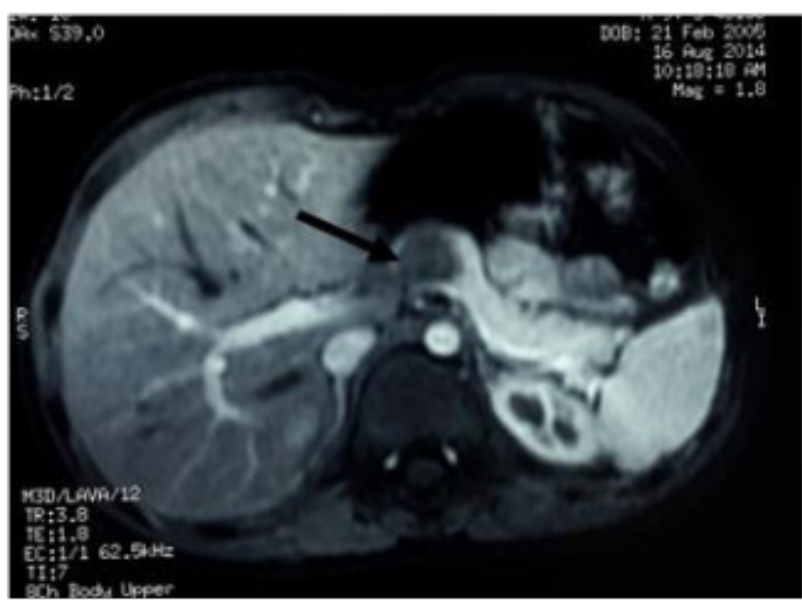

Figure 3 Contrast MRI of the upper abdomen. Arrow shows the tumor.

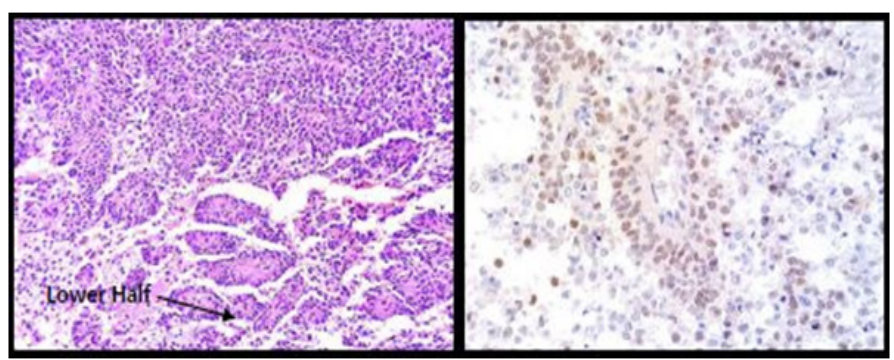

Figure 4 Left: microphotography showing 2 zones: neoplastic cells with solid patterns on upper half, and homogenous pseudo papillary pattern lower half. Right: microphotography exhibits positive cycline $\mathrm{dl}$.

\section{Discussion}

SPNP are slow growing malignant exocrine "borderline" neoplasms with a good prognosis, that represent $1-2 \%$ of pancreatic tumors and takes years to doubles its size. ${ }^{1,2,4,7}$ SPNP are prevalent in women on the second-third decade of live. ${ }^{2}$ Over the years they received several names such as epithelial papillary neoplasm, cystic papillary neoplasm, Frantz tumor, among others, until 1996 when
WHO categorized it as SPN. ${ }^{2-4}$ Its etiology is still unknown but may be related to sexual hormones. ${ }^{2}$ Its prevalence has been increasing over the years particularly in Asia; ${ }^{8}$ they are rare in children especially in males. ${ }^{5,9}$ From 500 cases of SPNP reported in a study only 35 been on children. ${ }^{3}$ Another review showed 718 cases of SPNP which 167 were children from Europe, EEUU and Japan. ${ }^{10}$ In Peru 629 cases have been reported, mostly of adult women. ${ }^{11}$ In this report we present two cases uncommon pediatric cases, a $6 \mathrm{y} / \mathrm{o}$ female and a $9 \mathrm{y} / \mathrm{o}$ male.

Clinical presentation can range from asymptomatic to abdominal pain, nausea, vomiting, jaundice, pancreatitis or palpable mass. It can be located on any part of the pancreas but usually present on tail, then around the head and neck. ${ }^{8}$ Diagnosis should be suspected on any mass inside the pancreas and ultrasound detects SPNP of more than 0.5-34.5 cm. ${ }^{10}$ Either a CT or MRI can be performed to discover the extension and infiltration of the tumor. Endoscopic ultrasound guided fine needle biopsy ${ }^{1-8,12}$ of the lesion usually allows the AP identify the solid and pseudo papillary patterns on hematoxylin-eosin stain ${ }^{9,13}$ and in some cases hemorrhagic, necrotic, or cystic areas can be found. ${ }^{1} \mathrm{IHC}$ is mandatory to rule out other malignancies ${ }^{10,14}$ Nonspecific markers for SPNP are: vimentin, CD56, $\alpha-1$ antitrypsin, neuron specific enolase (NSE), synaptophysin, $\alpha$-1-antichymotrypsin, fosfolipase $\mathrm{A} 2^{1-3,8-10,15}$ CD10, APC/ $\beta$-catenin, cycline $\mathrm{D} 1,2,7-10$ galectin- $3,{ }^{4}$ e-cadherin, progesterone receptor, ${ }^{8,13}$ cytokeratin. ${ }^{8}$ On the other hand tests are negative for: chromogranin A only found in neuroendocrine pancreatic tumors; ${ }^{2} \mathrm{CD} 99$, in pancreatic neuroectodermal tumors; ${ }^{9}$ and finally estrogen receptor; and, $\mathrm{Ki}-67$, pan cytokeratin are also negative. ${ }^{2,4,7-9}$ Tumor markers such as CA 19.9, CA 125, AFP and CEA are commonly within normal limits. ${ }^{15}$

SPNP may be clinically difficult to differentiate from other pancreatic neoplasms, especially serous microcystic adenoma, mucinous cystic neoplasm, intraductal papillary mucinous neoplasm, neuroendocrine cystic tumors, remaining SPNP the rarest one. ${ }^{9,11,12}$ Differential diagnosis also includes pancreatic teratoma and pancreatoblastoma; but when calcifications and an abdominal palpable mass are present SPNP must be suspected. ${ }^{7}$ Treatment involves the complete extraction of the tumor through a laparotomy or laparoscopy. Distal pancreatectomy, Whipple or Langmire procedures are the usual approaches. ${ }^{9,11,12}$ Metastases are rare, but liver, lymph nodes, ${ }^{9,10}$ peritoneum, ${ }^{9}$ hepatic portal vein and spleen ${ }^{10}$ have been described. In our cases no metastasis were found. Inpatient observation usually lasts around 7 days post-surgery ${ }^{11}$ and the prognosis is good in most of the cases. ${ }^{1-10,14-17}$ If metastasis is found chemotherapy and radiotherapy can be used allowing a 5 year survival between 6 months and 17 years. ${ }^{10}$

\section{Conclusion}

In spite of its rarity, when a pancreatic mass is found in children, the differential diagnosis should include SPN of the pancreas. Diagnosis can be challenging but technologic advances such as EUS can be helpful. Prognosis after complete resection is good.

\section{Acknowledgement}

None.

\section{Conflict of interest}

Authors declare no conflicts of interests. 


\section{Funding source}

Self-funded.

\section{Financial disclosure}

None of the authors received financial aid to this article.

\section{Contributors' statements}

a. Valer-Montoya, Catherine: Carried the first draft and gave approval for manuscript submission.

b. Quiroz-Portella, Rafael: Carried the first draft and gave approval for manuscript submission.

c. Alvarado Germán F: Gave significant contributions, continuous feedback, and gave final approval for submission.

d. Díaz-Ferrer, Javier: Gave significant contributions, continuous feedback, and gave final approval for submission.

e. Carranza, Mariela: Gave significant contributions with imaging, continuous feedback, and gave final approval for submission.

f. Palomino-Portilla, Eugenio: Gave significant contributions, continuous feedback, and gave final approval for submission.

g. Piscoya Alejandro: Gave significant contributions, continuous feedback, and gave final approval for submission.

\section{References}

1. Mahida JB, Thakkar RK, Walker J, et al. Pseudopapillary neoplasm of the pancreas in pediatric patients: A case report and institutional case series, $J$ Ped Surg Case Reports. 2015;3(4):149-153.

2. Zhang JB, Shang D, Yeo TP, et al. A Persistent Solid Pseudopapillary Tumor of the Pancreas : Case Report and Brief Literature Review. Case Reports in Pancreatic Cancer. 2015;1(1):11-15.

3. Acuña R, Soto P, Muñoz V, et al. Tumor sólido pseudopapilar de páncreas, reporte de un caso. Rev Chil Pediatr. 2008;79(4):404-408.

4. Camacho JF, Duarte JC, Hidalgo JF, et al. Tumor sólido pseudopapilar del páncreas pediátrico. Presentación de un caso y revisión en la literatura. Bol. Med. Hosp. Infant. Mex 2010;67(2):133-141.
5. Karadeniz-cerit K, Ergelen R, Kalyoncu A, et al. Solid pseudopapillary tumor of the pancreas: a rare entity. Turk J Pediatr. 2014;56(3):310-312.

6. Kim Y, Moon SB. Incidental detection of a small solid pseudopapillary neoplasm of the pancreas after a traffic accident in a 12-year-old girl : a case report. Int Med Case Rep J. 2015;8:259-261.

7. Vassos N, Agaimy A, Klein P, et al. Solid Pseupapillary Neoplasm of the pancreas case series and literature review on an enigmatic entity. Int $J$ Clin Exp Pathol. 2013;6(6):1051-1059.

8. Nakeeb A, Wahab M, Elkashef W, et al. Solid pseudopapillary tumour of the pancreas: Incidence, prognosis and outcome of surgery (single center experience). Int J Surg. Elsevier Ltd. 2013;11(6):447-457.

9. Volkan Adsay N. Cystic lesions of the páncreas. Mod Pathol. 2007;20:S71-S93.

10. Papavramidis T, Papavramidis S. Solid Pseudopapillary Tumors of the Pancreas: Review of 718 patients reportated in English literature. $\mathrm{J}$. Am Coll Sur. 2005;200(6):965-972.

11. Targaronaj, Poggi L, Garatea R, et al. Tumores Sólidos Pseudopapilares de Páncreas Reporte de 7 casos y revisión de Literatura. Rev. Gastroenterol. Perú. 2007;27(2):185-190.

12. Llatas J, Palomino A, Frisancho O. Tumor de Frantz: Neoplasia Sólida Pseudopapilar de Páncreas. Rev. Gastroenterol. Perú. 2011;31(1):56-60.

13. Spătaru RI, Enculescu A, Popoiu MC. Gruber-Frantz tumor: a very rare pathological condition in children. Rom J Morphol Embryol. 2014;55(4):1497-1501.

14. Bellarbi S, Sina M, Jahid A, et al. Tumeur de Frantz: deux nouveaux cas. Pan Afr Med J. 2013;14:7.

15. Park JY, Kim SG, Park J. Solid pseudopapillary tumor of the pancreas in children: 15-year experience at a single institution with assays using an immunohistochemical panel. Ann Surg Treat Res. 2014;86(3):130-135.

16. Reaño G, De Vinatea J, Arenas J, et al. Tumor Sólido Pseudopapilar del Páncreas: ¿Una Neoplasia de Bajo Potencial Maligno? Rev. Gastroenterol. Perú. 2011;31(1):61-71.

17. Licham MA, Sanchez Lihon J, Celis Zapata J. Tumor Sólido Pseudopapilar de Páncreas en el Instituto Nacional de Enfermedades Neoplásicas. Rev. Gastroenterol. Perú. 2008;28(4):356-361. 